\title{
ANALISIS DAN IMPLEMENTASI NETWORK SECURITY SYSTEM MENGGUNAKAN TEKNIK HOST-BASED INTRUSION DETECTION SYSTEM (HIDS) BERBASIS CLOUD COMPUTING
}

\author{
Mamay Syani ${ }^{1}$, Ali Muhammad Ropi ${ }^{2}$ \\ Program Studi Teknik Informatika ${ }^{1,2}$ \\ Politeknik TEDC Bandung, Jl. Politeknik - Pasantren KM. 2, Cibabat, Cimahi Utara, Kota \\ Cimahi msyani@poltektedc.ac.id ${ }^{1}$, alimr20021996@gmail.com²
}

Abstrak

Cloud Computing merepresentasikan teknologi untuk menggunakan infrastruktur komputasi dengan cara yang lebih efisien, Di sisi lain, arsitektur yang rumit dan terdistribusi semacam itu menjadi target yang menarik bagi para penyusup Cyberattacks. Penelitian ini melakukan analisis dan membangun sistem keamanan jaringan infrastruktur Cloud computing pada studi kasus di sektor pendidikan. Infrastruktur dibangun berdasarkan kebutuhan pengguna yang diperoleh melalui metode wawancara. Metodologi penelitian yang digunakan yaitu metodologi $N D L C$ yang terdiri dari 6 tahap namun dalam penelitian ini hanya memakai 5 tahapan dari metodologi NDLC. Hasil pengujian menunjukkan bahwa sistem keamanan jaringan yang dibangun sudah berhasil dan sistem Cloud yang bangun memenuhi user requirement. hasil uji terhadap kinerja sistem menunjukan bahwa pada parameter keakurasian pendeteksian bahwa sistem OSSEC dapat mendeteksi secara akurat dari serangan yang dilakukan penguji, pada parameter kecepatan pendeteksian bahwa sistem OSSEC lumayan cepat dalam mendeteksi adanya ancaman yang masuk, sedangkan pada parameter penggunaan sumber daya bahwa sistem OSSEC mengambil sedikit sekali penggunaan $C P U$ dan $R A M$ sehingga tidak memberatkan server, hasil observasi juga menunjukan bahwa sistem OSSEC yang dibangun berjalan dengan baik, berdasarkan dari observasi yang dilakukan oleh penulis hasil yang didapat terdapat sebanyak 620 peringatan pengintaian, 38849 peringatan authentication control, 569 peringatan attack/misue, 9018 peringatan Access Control, 0 peringatan Network Control, 230 peringatan System Monitor, dan 0 peringatan Policy Violation

Kata kunci :

Cloud Computing, IDS, HIDS, OSSEC

\begin{abstract}
Cloud Computing represents the technology for using computing infrastructure in a way that is more efficient, on the other hand, the complicated architecture of distributed and that kind of became a target of interest to intruders Cyberattacks. The research and analysis of building systems network security infrastructure Cloud computing case study on the education sector. The infrastructure was built based on the needs of users obtained through the method of interview. Research methodology used i.e. the NDLC methodology consists of 6 stages but in this study only wore 5 stages of the NDLC methodology. The test results show that the network security system constructed already managed and Cloud systems that meet the user's requirement, wake up. test results against the performance of the system indicates that the accuracy of the detection parameter on a system that can accurately detect the OSSEC from examiners, attack on parameters of speed detection system that fairly fast in OSSEC detect any incoming threats, whereas on the parameters of the use of resources that the system takes so little use of the OSSEC CPU and RAM so as not to burden the server, the results also showed that the observation system for OSSEC which was built runs well, based on the observations made by the author of the results obtained there were as many as 620 warning reconnaissance, 38849 warning authentication control, 569 warning attack/misue, 9018 warning Access Control, 0 warning Network Control, 230 Warning System monitors, and 0 warnings Policy Violation.
\end{abstract}

Keywords :

Cloud Computing, IDS, HIDS, OSSEC.

\section{PENDAHULUAN}

Cloud computing merupakan sebuah model untuk kenyamanan, akses jaringan on-demand untuk menyatukan pengaturan konfigurasi sumber daya komputasi seperti, jaringan, server, media penyimpanan, aplikasi, dan layanan yang dapat dengan cepat ditetapkan dan dirilis dengan usaha manajemen yang minimal atau interaksi dengan penyedia layanan [1]

Tetapi dari kemudahan yang ditawarkan oleh Cloud computing tersebut ada satu masalah krusial dalam Cloud computing, yaitu Security Issue. Karena sifat Cloud computing yang semua orang dapat menggunakannya dan karena sifat internet itu sendiri yang bersifat terbuka, sehingga membuka potensi celah keamanan bahwa tidak semua orang yang menggunakan internet itu berniat baik. Terkadang ada yang menggunakan internet untuk tujuan menyerang dan menyusup ke dalam jaringan sehingga dapat menyebabkan performa jaringan tersebut menurun atau bahkan membuat jaringan tersebut lumpuh.

Salah satu metode keamanan untuk mengamankan suatu jaringan adalah menggunakan IDS, IDS merupakan suatu sistem keamanan yang dimana apabila ada sesuatu perilaku mencurigakan yang tidak sesuai dengan rules yang diterapkan pada jaringan tersebut, maka IDS akan memberikan alert serta apabila memungkinkan memblokir 
alamat $I P$ yang melakukan serangan tersebut. Terdapat dua teknik yang digunakan dalam IDS yaitu, NIDS dan HIDS, $H I D S$ jauh lebih baik dalam mendeteksi dan merespon serangan jangka panjang seperti pencurian data. HIDS juga mampu melakukan pemeriksaan sistem tambahan yang hanya bisa dilakukan bila aplikasi IDS dipasang pada host, seperti file integrity checking, registry monitoring, log analysis, rootkit detection dan active response[2]

Berdasarkan uraian diatas penulis bermaksud untuk menggunakan Cloud computing sebagai perantara untuk menganalisis dan mengimplementasikan sistem keamanan jaringan menggunakan teknik Host-Based Intrusion Detection System dari IDS dengan software OSSEC sebagai tools keamanan jaringannya dengan mengambil studi kasus jaringan di Politeknik TEDC

\section{TINJAUAN PUSTAKA.}

\section{A. Keamanan Jaringan Komputer}

Keamanan Jaringan adalah komponen yang paling vital dalam keamanan informasi karena bertanggung jawab untuk mengamankan semua informasi melewati komputer berjejaring. Keamanan Jaringan mengacu pada semua fungsi perangkat keras dan perangkat lunak, karakteristik, fitur, prosedur operasional, akuntabilitas, tindakan, kontrol akses, dan administrasi dan manajemen kebijakan yang diperlukan untuk memberikan tingkat perlindungan yang dapat diterima untuk perangkat keras dan perangkat lunak, dan informasi dalam jaringan.

Masalah keamanan jaringan dapat dibagi secara kasar menjadi empat bidang yang saling terkait: kerahasiaan, otentikasi, nonrepudiation, dan integrity control. Kerahasiaan berkaitan dengan menjaga informasi dari tangan dari pengguna yang tidak berhak Inilah yang biasanya terlintas dalam pikiran ketika orang memikirkan keamanan jaringan. Otentikasi berhubungan dengan menentukan siapa yang Anda ajak bicara sebelum mengungkapkan informasi sensitif atau memasuki kesepakatan bisnis. Nonrepudiasi berurusan dengan tanda tangan Integritas Pesan: Sekalipun pengirim dan penerima saling mengotentikasi, mereka juga ingin memastikan bahwa isi komunikasi mereka tidak berubah

\section{B. Definisi Intrusion Detection Sistem (IDS)}

Intrusion detection (ID) singkatnya adalah usaha mengidentifikasi adanya penyusup yang memasuki sistem tanpa otorisasi (misal cracker) atau seorang user yang sah tetapi menyalahgunakan (abuse) privelege sumber daya sistem (misal insider threath) [3]. Intrusion Detection Sistem (IDS) atau sistem deteksi penyusup adalah sistem komputer (bisa merupakan kombinasi software dan hardware) yang berusaha melakukan deteksi penyusupan. IDS akan melakukan pemberitahuan saat mendeteksi sesuatu yang dianggap sebagai mencurigakan atau tindakan ilegal. IDS tidak melakukan pencegahan terjadinya penyusupan. Pengamatan untuk melakukan pemberitahuan itu bergantung pada bagaimana baik melakukan konfigurasi IDS[3]

Ada dua teknik IDS yaitu Network based IDS (NIDS) dan Host based IDS (HIDS).

\section{OSSEC}

OSSEC adalah open source HIDS. Perangkat lunak ini melakukan log analysis, file integrity checking, policy monitoring, rootkit detection, real-time alerting dan active response. OSSEC memberikan fungsi yang sama seperti SIEM (Security Information and Event Management) dan STRM (Security Threat Response Management). Aplikasi ini menggunakan arsitektur client-server. Komunikasi antara keduanya menggunakan protokol UDP dengan port 1514 dan dienkripsi menggunakan algoritma symmetric key Blowfish. Agent yang dimonitor dapat berjalan pada bermacam-macam sistem operasi, tetapi server haruslah dipasang pada sistem operasi BSD/Linux/Unix[2]

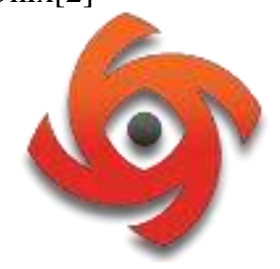

Gambar 1 Logo OSSEC (Sumber : https://ossec.github.io)

\section{Cloud Computing}

Sebuah model untuk kenyamanan, akses jaringan ondemand untuk menyatukan pengaturan konfigurasi sumber daya komputasi (seperti, jaringan, server, media penyimpanan, aplikasi, dan layanan) yang dapat dengan cepat ditetapkan dan dirilis dengan usaha manajemen yang minimal atau interaksi dengan penyedia layanan.[4]

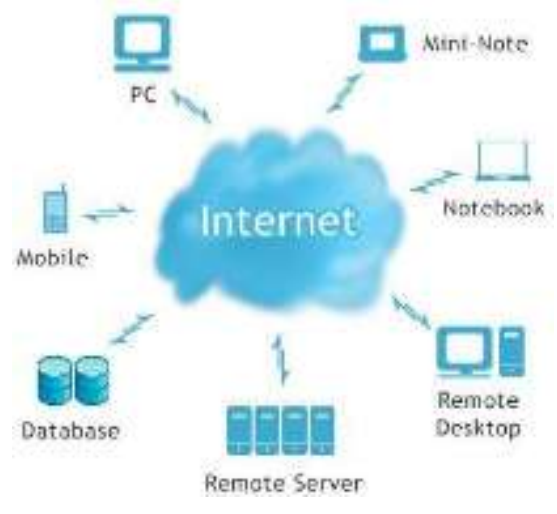

Gambar 2 Cloud Computing [1]

\section{E. Karakteristik Cloud Computing}

Lima karakteristik penting dari Cloud Computing [1]yaitu :

- On-demand self-service.

Konsumen dapat menentukan kemampuan komputasi secara sepihak, seperti server time dan network storage, 
secara otomatis sesuai kebutuhan tanpa memerlukan interaksi manusia dengan masing-masing penyedia layanan.

- Broad network access.

Kemampuan yang tersedia melalui jaringan dan diakses melalui mekanisme standar yang mengenalkan penggunaan berbagai platform (misalnya, telepon selular, tablet, laptop, dan workstations).

- Resource pooling.

Penyatuan sumberdaya komputasi yang dimiliki penyedia untuk melayani beberapa konsumen virtual yang berbeda, ditetapkan secara dinamis dan ditugaskan sesuai dengan permintaan konsumen.

- Rapid elasticity.

Kemampuan dapat ditetapkan dan dirilis secara elastis, dalam beberapa kasus dilakukan secara otomatis untuk menghitung keluar dan masuk dengan cepat sesuai dengan permintaan

- Measured Service.

Sistem Cloud Computing secara otomatis mengawasi dan mengoptimalkan penggunaan sumber daya dengan memanfaatkan kemampuan pengukuran (metering) pada beberapa tingkat yang sesuai dengan jenis layanan (misalnya, penyimpanan, pemrosesan, bandwidth, dan account pengguna aktif)

\section{F. Model Layanan Cloud Computing}

Tiga model layanan dari Cloud Computing [1]yaitu :

- Cloud Software as a Service (SAAS). Kemampuan yang diberikan kepada konsumen untuk menggunakan aplikasi penyedia dapat beroperasi pada infrastruktur Cloud.

- Cloud Platform as a Service (PAAS). Kemampuan yang diberikan kepada konsumen untuk menyebarkan aplikasi yang dibuat konsumen atau diperoleh ke infrastruktur Cloud Computing menggunakan bahasa pemrograman dan peralatan yang didukung oleh provider.

- Cloud Infrastructure as a Service (IAAS). Kemampuan yang diberikan kepada konsumen untuk memproses, menyimpan, berjaringan, dan sumber komputasi penting yang lain, dimana konsumen dapat menyebarkan dan menjalankan perangkat lunak secara bebas, yang dapat mencakup sistem operasi

\section{ANALISIS DAN PERANCANGAN}

\section{A. Analisis Sistem}

Sistem ini dirancang untuk melakukan pendeteksian dan monitoring terhadap sejumlah aktivitas mencurigakan yang sedang terjadi pada server SIAKAD, server KEPEGAWAIAN, dan server PDDIKTI, fungsi dari ketiga server tersebut diantaranya, server SIAKAD digunakan untuk melakukan pengolahan data dan informasi kampus bagi kepentingan civitas akademika serta kepentingan pihak ketiga (pemerintah dan publik), Server KEPEGAWAIAN merupakan bagian data yang berkaitan dengan pengelolaan data, manajemen dan administrasi kepegawaian, server PDDIKTI digunakan sebagai pusat kumpulan data penyelenggara pendidikan, port yang dibuka pada ketiga server diantaranya, untuk server SIAKAD port $80(H T T P)$, port $21(F T P)$, port $22(S S H)$, port 3306 (MYSQL), untuk server KEPEGAWAIAN port 80(HTTP), port 21(FTP), port 22 (SSH), port 3306 (MYSQL), sedangkan untuk server PDDIKTI port 8082 (HTTP),port 21 (FTP), port 22 (SSH), port 5432 (postgresql).

Mula mula sistem akan menangkap paket-paket data yang masuk kedalam sistem, kemudian paket data tersebut akan di deteksi berdasarkan rules yang sudah ada, jika paket data sudah terdeteksi dan sesuai dengan rules yang ada maka sistem akan memberikan peringatan kepada administrator dan juga sistem akan membuat log terhadap paket data untuk dikaji lebih jelas oleh administrator, apabila paket data yang dideteksi tidak sesuai dengan rule maka tidak akan ada pemberitahuan kepada administrator.

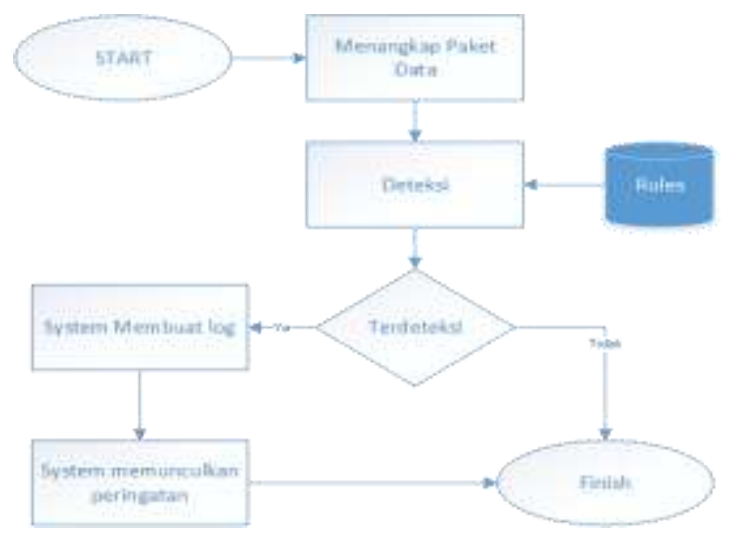

Gambar 3 Diagram alur sistem jaringan yang akan digunakan

\section{B. Analisis Kebutuhan Sistem}

Analisis kebutuhan dilakukan untuk mengetahui proses identifikasi dan evaluasi permasalahan yang ada, sehingga dapat dibangun sebuah sistem yang sesuai dengan yang diharapkan

1) Kebutuhan Pengguna: Daftar kebutuhan pengguna diperoleh dengan melakukan survei ke lapangan dengan metode wawancara,. Berdasarkan hasil wawancara yang dilakukan pada tanggal 16 April 2018 diperoleh daftar kebutuhan sebagai berikut:

- Tersedianya 3 buah server untuk keperluan kampus, yaitu server SIAKAD , Kepegawaian, dan PDDIKTI

- server SIAKAD digunakan untuk melakukan pengolahan data dan informasi kampus bagi kepentingan civitas akademika serta kepentingan pihak ketiga (pemerintah dan publik), Server KEPEGAWAIAN merupakan bagian data yang berkaitan dengan pengelolaan data, manajemen dan administrasi kepegawaian, server PDDIKTI digunakan sebagai pusat kumpulan data penyelenggara pendidikan. 
- Port yang di buka pada ketiga server diantaranya

TABEL I

PORT YANG DIBUKA PADA SERVER

\begin{tabular}{|l|l|l|}
\hline \multicolumn{3}{|c|}{ Server } \\
\hline SIAKAD & KEPEGAWAIAN & PDDIKTI \\
\hline port 80 $(H T T P)$ & port 80 $(H T T P)$ & port 8082 $(H T T P)$ \\
port 21 $(F T P)$ & port 21 $(F T P)$ & port 21 $(F T P)$ \\
port 22 $($ SSH $)$ & port 22 $($ SSH $)$ & port 22 (SSH) \\
port 3306 & port 3306 $($ MYSQL) & $\begin{array}{l}\text { port 5432 } \\
(\text { postgresql })\end{array}$ \\
\hline
\end{tabular}

- Sistem keamanan yang dirancang diharapkan dapat mendeteksi adanya serangan, dan dapat memonitoring setiap perubahan yang terjadi pada server

2) Perangkat Keras : Adapun spesifikasi minimum dari perangkat keras adalah sebagai berikut:

TABEL II

SPESIFIKASI PERANGKAT KERAS

\begin{tabular}{|c|cc|c|c|}
\hline \multicolumn{2}{|c|}{ Perangkat } & \multicolumn{2}{c|}{ SPESIFIKASI } \\
\cline { 3 - 5 } & $\begin{array}{c}\text { 1. } \\
\text { Cloud Server }\end{array}$ & CLIENT \\
\hline \multirow{3}{*}{ PC } & & Memory (RAM) & $1 \mathrm{~GB}$ & $2 \mathrm{~GB}$ \\
\cline { 2 - 5 } & 2. & Processor & $2 \mathrm{GHz}$ & $2 \mathrm{GHz}$ \\
\cline { 2 - 5 } & 3. & Harddisk & $25 \mathrm{~GB}$ & $50 \mathrm{~GB}$ \\
\hline \multirow{2}{*}{ Jaringan } & 1. & Ethernet Card & enp0s3 & $\begin{array}{c}\text { Wifi } \\
\text { Adapter }\end{array}$ \\
\hline
\end{tabular}

3) Perangkat Software: Perangkat lunak yang digunakan dalam pengujian ini adalah:

TABEL III

SPESIFIKASI PERANGKAT LUNAK

\begin{tabular}{|c|l|c|l|}
\hline No & Software & Versi & Keterangan \\
\hline 1 & Ubuntu & 16.04 .4 & $\begin{array}{l}\text { Sistem Operasi yang } \\
\text { digunakan sebagai OS untuk } \\
\text { Server PDPDPT Server } \\
\text { KEPEGAWAIAN, dan } \\
\text { Server PDDIKTI, }\end{array}$ \\
\hline 2 & OSSEC-HIDS & 2.9 .3 & Aplikasi IDS server \\
\hline 3 & OSSEC-WUI & 0.8 & $\begin{array}{l}\text { Web-Based Monitoring } \\
\text { OSSEC }\end{array}$ \\
\hline 4 & Kali Linux & 2017.3 & $\begin{array}{l}\text { Sistem Operasi yang } \\
\text { digunakan sebagai OS untuk } \\
\text { menyerang server }\end{array}$ \\
\hline 5 & NMAP & 7.60 & $\begin{array}{l}\text { Aplikasi yang akan } \\
\text { digunakan untuk melakukan } \\
\text { scaning port }\end{array}$ \\
\hline 7 & Wireshark & 2.4 .2 & $\begin{array}{l}\text { Tools yang digunakan untuk } \\
\text { menyerang } \\
\text { keamanan kerapuhan } \\
\text { digunakan untuk Sniffing } \\
\text { packet }\end{array}$ \\
\hline
\end{tabular}

\section{Perancangan Topologi}

Pada tahap ini penulis melakukan perancangan topologi yang akan digunakan pada tahap implemetasi dan pengujian

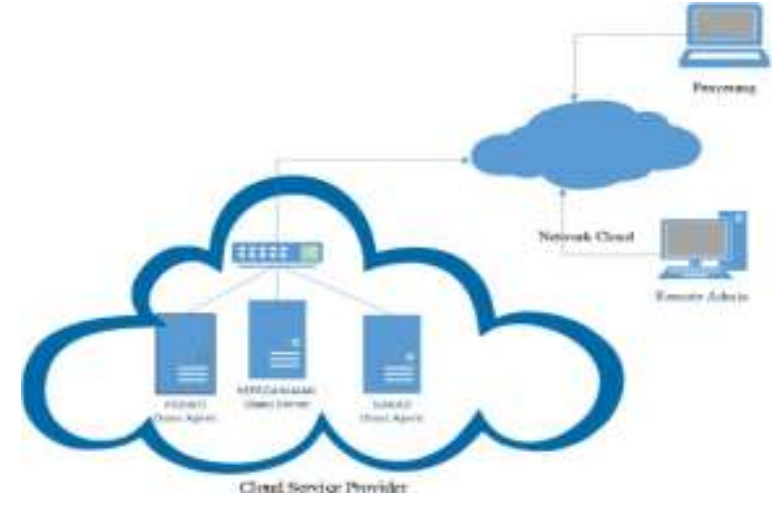

Gambar 4 Topologi jaringan Cloud yang akan di bangun

Sistem Cloud yang akan dibangun akan mengimplementasikan sistem keamanan jaringan menggunakan teknik Host-Based Intrusion Detection System dari IDS dengan software OSSEC sebagai tools keamanan jaringannya pada ketiga server tersebut. OSSEC Server digunakan sebagai pusat pemberitahuan serangan kepada ketiga server, sedangkan OSSEC agent mengirimkan pemberitahuan serangan ke OSSEC Server, untuk Remote Admin dapat mengakses server dimanapun asalkan terkoneksi ke internet

\section{Proses Instalasi}

Secara garis besar tahapan instalasi sistem terlihat seperti Gambar 6.
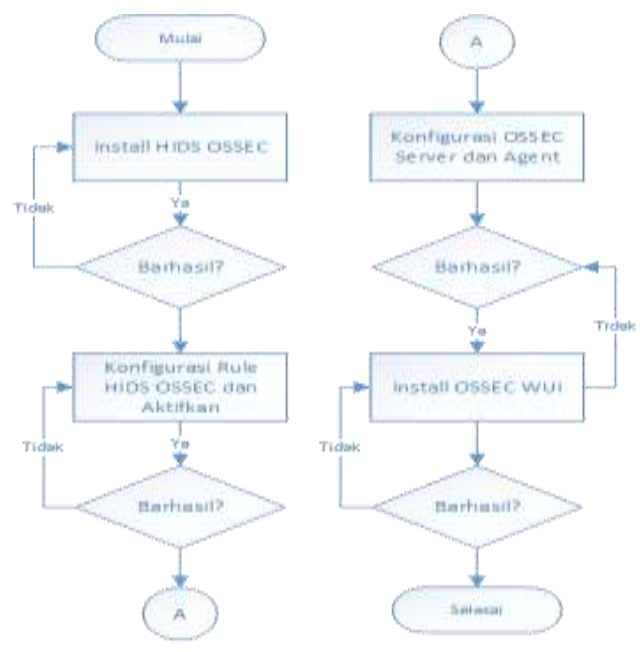

Gambar 5 Diagram alur pembangunan instalasi sistem

Proses pembangunan instalasi sistem dimulai dengan melakukan instalasi sistem dan software pendukung, setelah itu melakukan konfigurasi sistem keamanan OSSEC seperti mengkonfigurasi active response dari software OSSEC agar sistem dapat memberikan pemberitahuan secara berkala apabila terjadi perubahan pada server atau terjadi serangan, dan mengaktifkannya, setelah dikonfigurasi selanjutnya adalah proses konfigurasi OSSEC Server dan OSSEC Agentnya, agar 
server yang dijadikan agen OSSEC dapat termonitor oleh OSSEC server maka harus didaftarkan terlebih dahulu pada server yang dijadikan OSSEC Servernya, setelah itu di OSSEC agen akan dilakukan import key yang telah dibuat di OSSEC server sebelumnya agar OSSEC server dan OSSEC agen dapat mengirimkan dan menerima pemberitahuan apabila terjadi perubahan atau terjadi serangan, setelah selesai selanjutnya melakukan instalasi OSSEC WUI untuk memudahkan proses monitoring.

\section{E. Simulation Prototyping}

Pada tahap ini penulis membangun prototype dari sistem yang akan dibangun. Proses simulasi berguna untuk menghndari kesalahan/kegagalan pada tahapan implementasi Penulis menggunakan aplikasi GNS3 dikombinasikan dengan aplikasi virtualisasi VirtualBox, dimana aplikasi GNS3 digunakan untuk merancang topologi yang akan dibangun, sedangkan aplikasi VirtualBox untuk menjalankan sistem operasinya

\section{IMPLEMENTASI DAN PENGUJIAN}

\section{A. Implementasi Sistem}

1) Spesifikasi Perangkat Virtual : Spesifikasi perangkat virtual digunakan dalam tahapan implementasi terinci pada tabel IV

TABEL IV

SPESIFIKASI PERANGKAT VIRTUAL PADA LINGKUNGAN IMPLEMENTASI

\begin{tabular}{|c|c|c|c|c|}
\hline No & Komponen & $\begin{array}{c}\text { Server } \\
\text { Kepegawaian }\end{array}$ & $\begin{array}{c}\text { Server } \\
\text { PDDIKTI }\end{array}$ & $\begin{array}{c}\text { Server } \\
\text { SIAKAD }\end{array}$ \\
\hline 1 & Processor & $\begin{array}{l}\text { Intel(R) } \\
\text { Xeon(R) CPU } \\
\text { E5-26200@ } \\
2.00 \mathrm{GHz}\end{array}$ & $\begin{array}{l}\text { Intel(R) } \\
\text { Xeon(R) } \\
\text { CPU E5- } \\
2650 \text { v4 @ } \\
2.20 \mathrm{GHz}\end{array}$ & $\begin{array}{l}\text { Intel(R) } \\
\text { Xeon(R) } \\
\text { CPU E5- } \\
2630 \mathrm{~L} \mathrm{v2} \\
@ \\
2.40 \mathrm{GHz}\end{array}$ \\
\hline 2 & Memory & $1 \mathrm{~GB}$ & $1 \mathrm{~GB}$ & $1 \mathrm{~GB}$ \\
\hline 3 & Harddisk & $S S D 25 \mathrm{~GB}$ & $S S D 25 \mathrm{~GB}$ & $S S D 25 \mathrm{~GB}$ \\
\hline 4 & $O S$ & $\begin{array}{l}\text { Ubuntu } \\
16.04 .4 \text { x64 }\end{array}$ & $\begin{array}{l}\text { Ubuntu } \\
16.04 .4 \text { x64 }\end{array}$ & $\begin{array}{l}\text { Ubuntu } \\
16.04 .4 \\
\text { x64 }\end{array}$ \\
\hline 5 & Networking & $1 \mathrm{x}$ enp0s3 & $1 \mathrm{x}$ enp0s3 & $1 \mathrm{x}$ enp0s3 \\
\hline
\end{tabular}

2) Tahapan Implementasi : yang dilakukan pertama kali dilakukan pada tahap implementasi adalah menganalisis kebutuhan sistem dalam melakukan penelitian dan membuat daftar kebutuhan sistem yang digunakan untuk melakukan pengujian. Tahap berikutnya adalah melakukan instalasi sistem dan software pendukung, setelah itu melakukan konfigurasi sistem keamanan OSSEC dan mengaktifkannya, setelah itu melakukan instalasi OSSEC WUI untuk memudahkan proses monitoring. Hasil akhir pada tahap ini berupa Prototype IAAS yang selanjutnya akan dilakukan uji coba terhadap keakurasian, kecepatan pendeteksian, dan penggunaan sumberdaya $C P U$ dan $R A M$ untuk mengukur kinerja dari sistem keamanan yang dibangun

\section{B. Pengujian Sistem}

1) Spesifikasi Perangkat Keras: Spesifikasi perangkat keras dan perangkat lunak yang digunakan dalam pengujian terinci pada tabel $\mathrm{V}$

TABEL V

SPESIFIKASI PC CLIENT PADA LINGKUNGAN PENGUJIAN

\begin{tabular}{|l|l|l|}
\hline No & Komponen & \multicolumn{1}{c|}{ Client } \\
\hline 1 & Processor & $\begin{array}{l}\text { Intel(R) Core(TM) i3-2370M CPU @ } \\
2.40 \mathrm{GHz} \text { (4CPUs) }\end{array}$ \\
\hline 2 & Memory & 6GB \\
\hline 3 & Harddisk & $500 \mathrm{~GB}$ \\
\hline 4 & OS & $\begin{array}{l}\text { Windows 8.1 Pro 64-bit } \\
\text { Kali Linux 2017.3 }\end{array}$ \\
\hline 5 & Networking & $\begin{array}{l}1 \times \text { Qualcomm Atheros AR9485 } \\
802.11 \mathrm{~b} / \mathrm{g} / \mathrm{n} \text { WiFi Adapter }\end{array}$ \\
\hline
\end{tabular}

2) Data Hasil Uji Terhadap Kebutuhan Pengguna Terhadap Sistem : Berdasarkan hasil peng ujian yang dilakukan oleh penulis diperoleh data bahwa protoptype keamanan jaringan berbasis Cloud yang dibangun dapat berjalan sesuai dengan spesifikasi kebutuhan pengguna. Hasil uji terinci pada tabel VI

TABEL VI

HASIL PENGUJIAN KESESUAIAN KEBUTUHAN PENGGUNA

\begin{tabular}{|c|c|c|}
\hline No. & Kebutuhan Pengguna & Hasil \\
\hline 1 & Tersedianya 3 Server & $\mathrm{Ya}$ \\
\hline 2 & Ketiga Server dapat diakses dimana saja & Berhasil \\
\hline 3 & Jaringan Cloud dapat diakses oleh multiuser & Berhasil \\
\hline 4 & 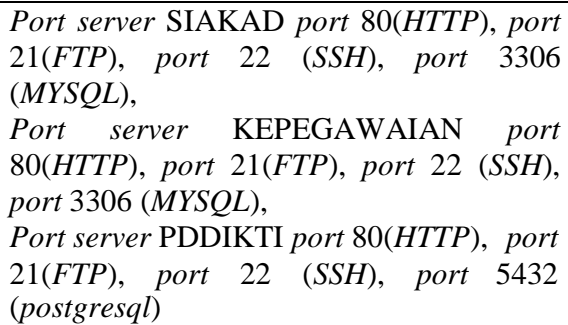 & $\mathrm{Ya}$ \\
\hline 5 & $\begin{array}{l}\text { Sistem dapat mendeteksi berbagai serangan } \\
\text { dan dapat memonitoring perubahan yang } \\
\text { terjadi pada server }\end{array}$ & Berhasil \\
\hline
\end{tabular}

3) Data hasil uji terhadap kinerja sistem

- Pengujian Kecepatan Pendeteksian

Pengujian untuk parameter kecepatan pendeteksian dilakukan dengan mengambil waktu yang dibutuhkan untuk software OSSEC mengetahui adanya serangan keserver, dalam tahap pengujian kecepatan pendeteksian ini penulis melakukan pengujian beberapa serangan ke server diantaranya scanning port menggunakan NMAP, Brute Force Attack menggunakan Armitage + Metasploit, Sniffing menggunakan Wireshark, dan mencoba salah satu serangan DDOS Attack yaitu HTTP FLOOD menggunakan Armitage+Metasploit, berikut adalah grafik hasil uji terhadap kecepatan pendeteksian 


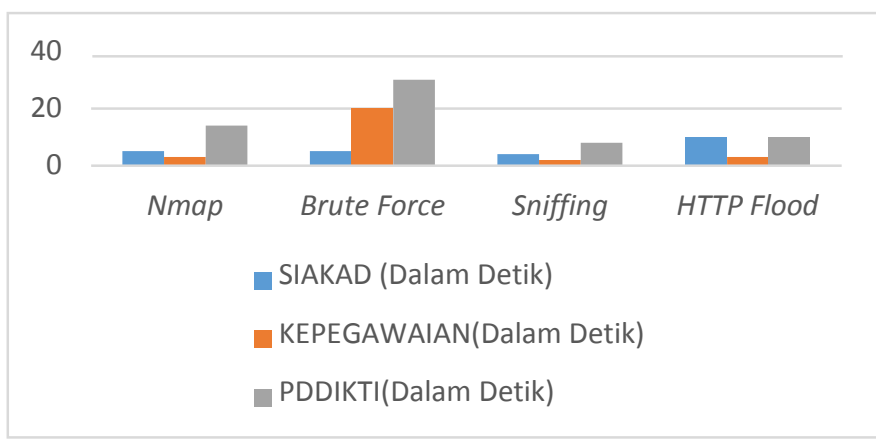

Gbr. 6 Grafik Hasil Pengujian Kecepatan Pendeteksian

- Pengujian penggunaan sumber daya

Pengujian penggunaan sumber daya dilakukan dengan mengambil berapa persen penggunaan $C P U$ dan $R A M$ yang digunakan sistem OSSEC pada saat terjadi serangan

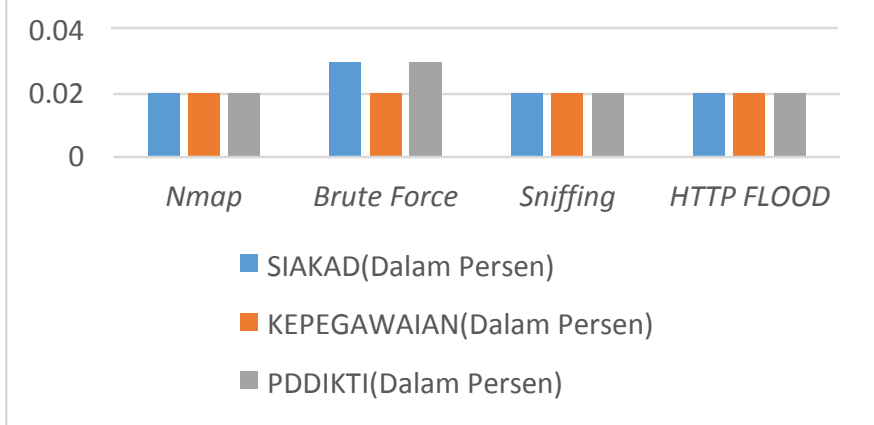

Gbr. 7 Grafik Hasil Pengujian penggunaan sumber daya

- Data Hasil Observasi

Untuk mengetahui software OSSEC bekerja dengan baik memonitor Cloud Server penulis melakukan observasi dengan menyalakan Cloud Server 2-4 jam per hari selama 14 hari, berikut adalah grafik data hasil observasi

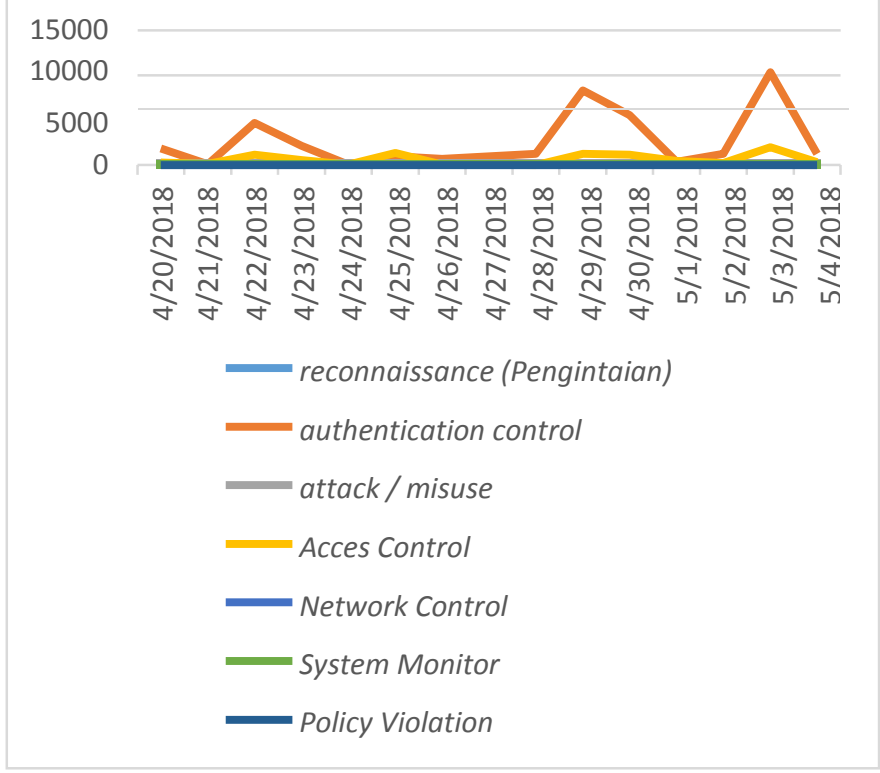

Gbr. 8 Grafik Data Hasil Observasi
Berdasarkan dari Observasi yang dilakukan oleh penulis pada tanggal 20 April - 4 Mei 2018, hasil yang didapat terdapat sebanyak 620 peringatan pengintaian, 38849 peringatan authentication control, 569 peringatan Attack/misue, 9018 peringatan Access Control, 0 peringatan Network Control, 230 peringatan System Monitor, dan 0 peringatan Policy Violation.

\section{KESIMPULAN}

Sistem keamanan jaringan yang dirancang dengan software OSSEC berbasis Cloud Computing, dimulai dari menganalisis kebutuhan dari sistem, dari analisis kebutuhan sistem tersebut dilakukan perancangan konfigurasi sistem, perancangan topologi, serta perancangan dari proses instalasi dari sistem yang akan dibangun. Dari hasil implementasi ini berupa Prototype IAAS yang selanjutnya dilakukan uji coba terhadap keakurasian, kecepatan pendeteksian, dan penggunaan sumberdaya $C P U$ dan $R A M$ untuk mengukur kinerja dari sistem keamanan yang dibangun. Dari hasil uji yang diperoleh bahwa server dapat mendeteksi adanya serangan dan dapat memonitoring setiap perubahan yang terjadi pada server ,Hasil uji dari fungsionalitas sistem menunjukkan bahwa IAAS yang dibangun telah sesuai dengan kebutuhan pengguna, untuk uji kinerja sistem didapatkan pada parameter keakurasian pendeteksian bahwa sistem OSSEC dapat mendeteksi secara akurat dari serangan yang dilakukan penguji, pada parameter kecepatan pendeteksian bahwa sistem OSSEC lumayan cepat dalam mendeteksi adanya ancaman yang masuk, sedangkan pada parameter penggunaan sumber daya bahwa sistem OSSEC mengambil sedikit sekali penggunaan $C P U$ dan $R A M$ sehingga tidak memberatkan server, hasil observasi juga menunjukan bahwa sistem OSSEC yang dibangun berjalan dengan baik, Berdasarkan dari Observasi yang dilakukan oleh penulis hasil yang didapat terdapat sebanyak 620 peringatan pengintaian, 38849 peringatan authentication control, 569 peringatan Attack/misue, 9018 peringatan Access Control, 0 peringatan Network Control, 230 peringatan System Monitor, dan 0 peringatan Policy Violation.

\section{REFERENSI}

[1] A. Ashari, H. Setiawan, J. Ilmu, F. Mipa, and U. G. Mada, "Cloud Computing : Solusi ICT ?," vol. 3, no. 2, pp. 336-345, 2011.

[2] S. I. L. Aulia Arip Rakhman, "Perancangan Ids Dengan Teknik Hids (Host Based Intrusion Detection System) Menggunakan Software Ossec," no. 604, pp. 1-7, 2015.

[3] K. D. Hartomo, U. Kristen, and S. Wacana, "Analisis Perancangan Perangkat Lunak Intrusion Detection System ( Ids ) Pada Jaringan Komputer Berbasis Teknologi Mobile," no. November, pp. 288-296, 2007.

[4] P. Mell and T. Grance, "The NIST Definition of Cloud Computing Recommendations of the National Institute of Standards and Technology," Nist Spec. Publ., vol. 145, p. 7, 2011. 